\title{
Test for Contagion with Applications to Equity Markets
}

\author{
Yu Ling Hsiao \\ School of Business \\ Macau University of Science and Technology \\ Macau \\ ylhsiao@must.edu.mo
}

\begin{abstract}
We empirically examine the episode of extraordinary turbulence in global financial markets during the subprime mortgage crisis of 2007. The analysis focuses on equity markets captured by daily movements for ten countries based on changes in correlation and coskewness of contagion tests. The results show that significant contagion effects are widespread from the US to both Asian and European equity markets based on coskewness change tests during the subprime mortgage crisis. Based on change in correlation test, there is significant evidence of contagion only to Asian equity markets during the subprime mortgage crisis.
\end{abstract}

Keywords-Contagion; Correlation change test; Coskewness change test; Financial Crisis

\section{INTRODUCTION}

Since the mid-1990s, international financial markets have experienced several episodes of financial disasters and distress, leading to huge capital losses around the world. The recent financial crises originate from diverse countries and regions including the Mexico in December 1994, East Asian in July 1997, Russia in 1998, Brazil in early 1999, Dot-Com in 2000, Turkey and Argentina in 2001, and the US of the subprime mortgage crisis in 2007. During these crises, financial market commentators and participants are concerned about the linkages between countries and financial markets, whether the crisis spillovers and cause extreme volatility in the world's financial markets.

In July of 2007, the US equity market plummeted, showing that this shock like virus may propagate to other markets or countries around the global. As shown in Figure 1, dramatic fluctuations of equity markets from the US can have a significant effect on markets of very different sizes and structures throughout the world. The figure shows that the dramatic market collapses during the crisis period and equity index fall simultaneously. There is an economic term "contagion", which means that source country suffering from crisis might transmit the shock to financial markets and countries.

The definition of contagion varies. Some economists have developed an approach that they compare the coefficient of correlation between two equity markets during the stable and crisis periods. Forbes and Rigobon (2002) applied this method and defined contagion as a significant increase in the crossmarket correlation during the period of crisis compared with the non-crisis period. Apart from comparison with correlation analysis approach, the identified role of skewness and high order moments in univariate distributions of asset returns during crises also are crucial feature for contagion addressed by Fry, Martin and Tang (2010). Here contagion is referred to significant changes in the higher order co-moments of the distribution for equity returns during a financial crisis compared to the non-crisis period. (Dornbusch, Park and Clasessens, 2000; Pericoli and Sbracia, 2003) There are some measures which focus on higher order interactions. Bae, Karolyi and Stulz (2003) develop the coexceedance tests. Knight, Lizieri and Satchell (2005) apply the framework of higher order moments and test the tails of the joint distribution using copulas.
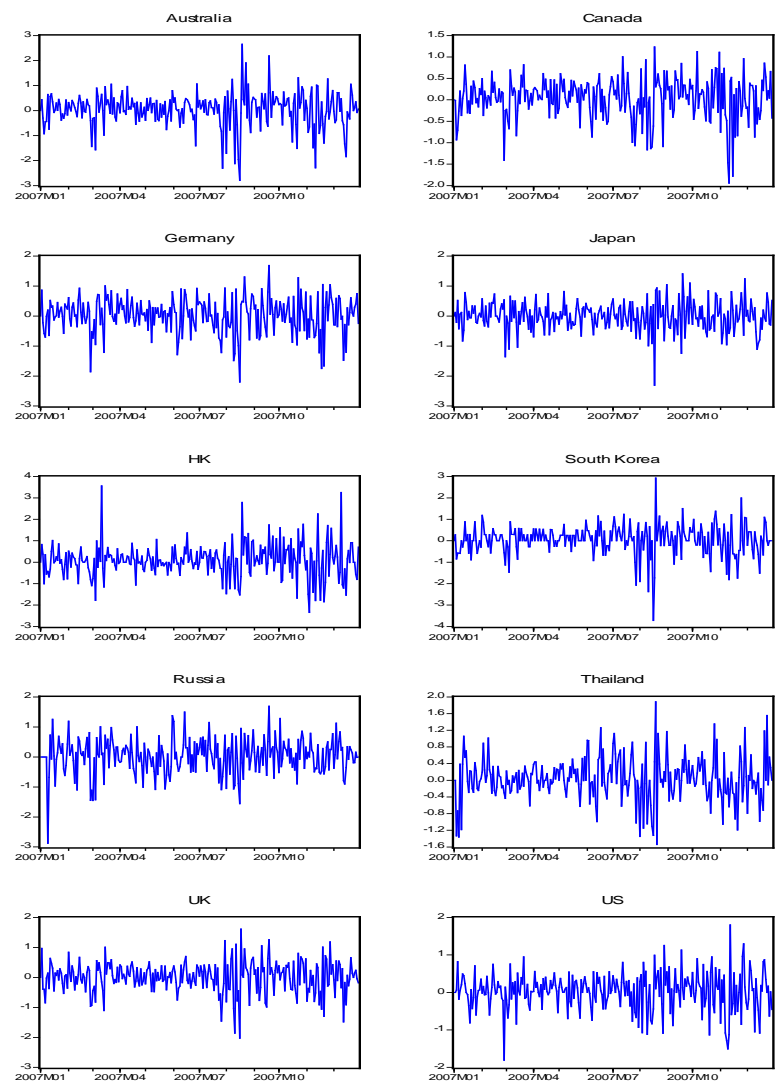

Fig. 1.Daily equity prices

Note: Daily equity prices (natural logs) - January 1, 2007 to December 31, 2007 
This paper applies two tests of contagion to test ten equity markets in Asian and European regions during the 2007 subprime mortgage crisis. The results show that there is significant evidence of contagion across equity markets in both Asian and European regions based on the coskewness change tests; while for the correlation test, the results show that there is evidence of contagion only to Asian region during the US subprime mortgage crisis.

The remainder of this paper is organized as follows. Section 2 discusses a number of preliminary empirical results including data filtering and identification of equity market shocks. Section 3 specifies the contagion test based on changes in correlation and coskewness. Section 4 presents the main empirical results. Section 5 contains some concluding comment.

\section{THE DATA AND SAMPLE}

The sample consists of daily equity price index $\left(P_{i, t}\right)$ collected from Datastream on ten stock markets (Australia, Canada, Germany, Hong Kong, Japan, South Korea, Russia, Thailand, the UK and the US). ${ }^{1}$ The sample data begins January 1, 2007 and ends December 31, 2007, a total sample of $\mathrm{T}=260$. Daily percentage equity returns of the $i^{t h}$ market are calculated as

$$
R_{i, t}=100\left(\ln \left(P_{i, t}\right)-\ln \left(P_{i, t-1}\right)\right)
$$

The effective sample of returns data begins January 4, 2007 and ends December 31, 2007. The sample period is allows to separate into two periods of the pre-crisis and crisis. The precrisis and crisis dates are based on Baig and Goldfajn (1999) and Dungey et al (2007). The non-crisis period is from January 2, 2007 to July 25, 2007 and the crisis period is from July 26, 2007 to December 31, 2007. Table 1 presents descriptive statistics for returns on ten equity markets from January 1, 2007 to December 31, 2007. The table shows that average daily returns of the equity indices decrease and volatility increases during the crisis period compared with the non-crisis period for all of the cases except for Russia.

TABLE I. DESCRIPTIVE STATISTICS

\begin{tabular}{|l|r|r|r|r|}
\hline & \multicolumn{2}{|c|}{ Non-crisis } & \multicolumn{2}{c|}{ Crisis } \\
\hline Markets & Mean & Variance & \multicolumn{1}{c|}{ Mean } & Variance \\
\hline Australia & 0.07 & 0.20 & -0.00 & 0.80 \\
\hline Canada & 0.06 & 0.14 & 0.01 & 0.35 \\
\hline Germany & 0.05 & 0.24 & -0.01 & 0.49 \\
\hline Japan & 0.01 & 0.15 & -0.04 & 0.34 \\
\hline Hong Kong & 0.07 & 0.31 & 0.10 & 0.99 \\
\hline Korea & 0.10 & 0.22 & -0.03 & 0.82 \\
\hline Russia & 0.02 & 0.38 & 0.04 & 0.31 \\
\hline Thailand & 0.08 & 0.19 & -0.01 & 0.37 \\
\hline
\end{tabular}

\footnotetext{
${ }^{1}$ The stock market indices used are: Hang Seng Stock Index, Thai SET Index, Russian RTS Index, FTSE 100, Korean KOSPI200, Deutsche Borse AG German Stock Exchange, Australian Stock Exchange ASX, S\&P/TSX Composite Index, Japanese TSE index and the US NASDAQ.
}

\begin{tabular}{|l|r|r|r|r|}
\hline UK & 0.03 & 0.14 & -0.01 & 0.44 \\
\hline US & 0.04 & 0.14 & 0.01 & 0.40 \\
\hline
\end{tabular}

Note: The non-crisis period is from January 2, 2007 to July 25, 2007 and the crisis period is from July 26, 2007 to December 31, 2007

\section{CONTAgION TESTS}

In developing tests of contagion, two types are applied to equity markets during the subprime mortgage crisis. One is to test for changes in correlations (Forbes and Rigobon, 2002), denoted as FR. Another test is addressed by the Fry, Martin and Tang (2010), which is based on changes in coskewness or CS. The following notation is used in order to derive the contagion tests. $T_{x}$ and $T_{y}$ are the sample sizes of the stable and crisis periods, respectively. Also, $\mathrm{x}$ and $\mathrm{y}$ are the non-crisis and crisis periods, respectively. Finally, the sample correlation coefficient between two equity returns during a stable (low-volatility) period is $\hat{\rho}_{x}$ and during a crisis period (high-volatility) is $\hat{\rho}_{y}$.

\section{A. FR test based on changes in correlation}

The FR test is to compare the correlation of returns between two equity markets during the non-crisis period with the crisis period to gauge whether there is significant increase in the correlation during the crisis period. If the correlation increases significantly, there is market contagion between two markets. However, if there is no significant increase in correlation, then there is high level of market co-movements between two periods what we called interdependence (Forbes and Rigobon, 2002).

Consider testing for contagion from a source market $i$ to a recipient equity market $j$. Forbes and Rigonbon (2002) mentioned that an increase in volatility in equity return of the source market $i$ would lead to upward bias for correlation coefficient during the crisis period. In order to adjust this bias, Forbes and Rigobon derived the adjusted correlation, gives

$$
\hat{v}_{y \mid x_{i}}=\frac{\hat{\rho}_{y}}{\sqrt{1+\delta\left(1-\hat{\rho}_{y}^{2}\right)}}
$$

$\hat{v}_{y \mid x_{i}}$ is the adjusted correlation coefficient during the crisis period. $\delta=\left(s_{y, i}^{2}-s_{x, i}^{2}\right) / s_{x, i}^{2}$ is the proportional change in the volatility of returns in the source crisis market $i . s_{y, i}^{2}$ and $s_{x, i}^{2}$ are the sample variances of equity returns in market $i$ during the non-crisis and crisis periods, respectively.

Fry, Martin and Tang (2010) introduce the correlation change test of contagion based on the framework of Forbes and Rigobon (2002). The test statistic is to test for contagion from $i$ (a source market) to $j$ (a recipient market), gives

$$
\operatorname{FR}(\mathrm{i} \rightarrow \mathrm{j})=\left(\frac{\hat{v}_{y \mid x_{i}}-\hat{\rho}_{x}}{\sqrt{\operatorname{Var}\left(\hat{v}_{y \mid x_{i}}-\hat{\rho}_{x}\right)}}\right)^{2}
$$

Where

$$
\operatorname{Var}\left(\hat{v}_{y \mid x_{i}}-\hat{\rho}_{x}\right)=\operatorname{Var}\left(\hat{v}_{y \mid x_{i}}\right)+\operatorname{Var}\left(\hat{\rho}_{x}\right)-2 \operatorname{Cov}\left(\hat{v}_{y \mid x_{i}}, \hat{\rho}_{x}\right),
$$




$$
\begin{gathered}
\operatorname{Var}\left(\hat{v}_{y \mid x_{i}}\right)=\frac{1}{2} \frac{(1+\delta)^{2}}{\left[1+\delta\left(1-\hat{\rho}_{y}^{2}\right)\right]^{3}}\left[\frac{1}{T_{y}}\left(\left(2-\hat{\rho}_{y}^{2}\right)\left(1-\hat{\rho}_{y}^{2}\right)^{2}\right)\right. \\
\left.+\frac{1}{T_{x}}\left(\hat{\rho}_{y}^{2}\left(1-\hat{\rho}_{y}^{2}\right)^{2}\right)\right], \\
\operatorname{Var}\left(\hat{\rho}_{x}\right)=\frac{1}{T_{x}}\left(1-\hat{\rho}_{x}^{2}\right)^{2}, \\
\operatorname{Cov}\left(\hat{v}_{y \mid x_{i}}-\hat{\rho}_{x}\right)=\frac{1}{2} \frac{1}{T_{x}} \frac{\hat{\rho}_{x} \hat{\rho}_{y}\left(1-\hat{\rho}_{y}^{2}\right)\left(1-\hat{\rho}_{x}^{2}\right)(1+\delta)}{\sqrt{\left[1+\delta\left(1-\hat{\rho}_{y}^{2}\right)\right]^{3}}}
\end{gathered}
$$

To test that there is a significant change in correlation, the null and alternative hypotheses are

$$
\begin{gathered}
H_{0}: v_{y \mid x_{i}}=\rho_{x} \\
H_{1}: v_{y \mid x_{i}}>\rho_{x}
\end{gathered}
$$

Under the null hypothesis of no contagion, the correlation test of contagion is asymptotically distributed as $\operatorname{FR}(i \rightarrow j)$ $\stackrel{d}{\rightarrow} \chi_{1}^{2}$. If the value of the FR test statistic is larger than the critical value (3.84 at 5\% significant), we can conclude that there is financial market contagion from source market $i$ to a recipient market $j$.

\section{B. CS tests based on changes in coskewness}

The CS tests addressed by Fry, Martin and Tang (2010) are to compare the coskewness of returns during the crisis period compared with the non-crisis period. Two types of tests are specified, one is $C S_{1}$ and the other is $C S_{2}$, which is dependent on whether the equity market at the source of the crisis is expressed in accordance with returns or squared returns in computing coskewness.

The Fry, Martin and Tang (2010) test statistics $\left(C S_{1}\right.$ and $C S_{2}$ ) to test for contagion from $i$ (a source market) to $j$ (a recipient market) are

$$
\begin{aligned}
& C S_{1}\left(i \rightarrow j ; r_{i}^{1}, r_{j}^{2}\right)=\left(\frac{\hat{\psi}_{y}\left(r_{i}^{1}, r_{j}^{2}\right)-\hat{\psi}_{x}\left(r_{i}^{1}, r_{j}^{2}\right)}{\left.\sqrt{\frac{4 \hat{v}_{y \mid x_{i}}+2}{T_{y}}+\frac{4 \hat{\rho}_{x}^{2}+2}{T_{x}}}\right)^{2},}\right. \\
& C S_{2}\left(i \rightarrow j ; r_{i}^{2}, r_{j}^{1}\right)=\left(\frac{\hat{\psi}_{y}\left(r_{i}^{2}, r_{j}^{1}\right)-\hat{\psi}_{x}\left(r_{i}^{2}, r_{j}^{1}\right)}{\sqrt{\frac{4 \hat{v}_{y \mid x_{i}}+2}{T_{y}}+\frac{4 \hat{\rho}_{x}^{2}+2}{T_{x}}}}\right)^{2},
\end{aligned}
$$

where

$$
\begin{aligned}
& \hat{\psi}_{y}\left(r_{i}^{m}, r_{j}^{n}\right)=\frac{1}{T_{y}} \sum_{t=1}^{T_{y}}\left(\frac{y_{i, t}-\hat{\mu}_{y i}}{\hat{\sigma}_{y i}}\right)^{m}\left(\frac{y_{j, t}-\hat{\mu}_{y j}}{\hat{\sigma}_{y j}}\right)^{n} \\
& \hat{\psi}_{x}\left(r_{i}^{m}, r_{j}^{n}\right)=\frac{1}{T_{x}} \sum_{t=1}^{T_{x}}\left(\frac{x_{i, t}-\hat{\mu}_{x i}}{\hat{\sigma}_{x i}}\right)^{m}\left(\frac{x_{j, t}-\hat{\mu}_{x j}}{\hat{\sigma}_{x j}}\right)^{n}
\end{aligned}
$$

To test that there is a significant change in coskewness, the null and alternative hypotheses are

$$
\begin{aligned}
& H_{0}: \psi_{y}\left(r_{i}^{m}, r_{j}^{n}\right)=\psi_{x}\left(r_{i}^{m}, r_{j}^{n}\right) \\
& H_{1}: \psi_{y}\left(r_{i}^{m}, r_{j}^{n}\right) \neq \psi_{x}\left(r_{i}^{m}, r_{j}^{n}\right)
\end{aligned}
$$

Under the null hypothesis of no contagion, the coskewness tests of contagion are asymptotically distributed as $C S_{1}(i \rightarrow$ $j), C S_{2}(i \rightarrow j) \stackrel{d}{\rightarrow} \chi_{1}^{2}$.

\section{EMPIRICAL RESULTS}

The tests of contagion described in Section 3 are applied to equity market during the subprime mortgage crisis of 2007. The recent financial crisis occurred in mid-2007 was the US subprime mortgage crisis. This crisis had led to crash in stock market and transmitted the financial shocks to other markets or countries around the world.

The subprime mortgage crisis is from July 26, 2007 to December 31, 2007 and a stable period is from January 1, 2007 to July 25, 2007. These dates are based on Dungey et al (2007). Next, the data is filtered by using Vector Autoregressive Model (VAR), gives

$$
\begin{gathered}
X_{t}=\phi(L) X_{t}+\eta_{t}, \\
X_{t}=\left(x_{t}^{u s}, x_{t}^{j}, y_{t}^{u s}, y_{t}^{j}\right)^{\prime} .
\end{gathered}
$$

where $x_{t}^{u s}$ and $y_{t}^{u s}$ (source market) are the US equity returns during the non-crisis and crisis periods, $x_{t}^{j}$ and $y_{t}^{j}$ are the returns in recipient market $j$ during two periods. The recipient markets included are Australia, Canada, Germany, Hong Kong, Japan, South Korea, Russia, Thailand and the UK. $\phi(L)$ is a vector of lags and $\eta_{t}$ is a vector of reduced-form disturbances. Five lags are chosen based on the lag selection criterion of Akaike and Schwarz information. A 10-variate VAR with five lags is estimated in order to control the market fundamentals. The residuals estimated from VAR model are used in computing the Forbes and Rigobon contagion test statistic and the Coskewness contagion test statistics.

TABLE II. TESTS OF CONTAGION

\begin{tabular}{llcccc}
\hline \multirow{2}{*}{ Market } & \multicolumn{5}{c}{ Equity } \\
\cline { 2 - 6 } & \multicolumn{2}{c}{$F R^{(a)}$} & \multicolumn{2}{c}{$C S_{1}^{(b)}$} & $C S_{2}^{(c)}$ \\
\hline Australia & $3.50 *$ & 7.05 & $* *$ & 0.00 & \\
Canada & 0.03 & 0.67 & 4.36 & $* *$ \\
Germany & 0.55 & 1.55 & 9.22 & $* *$ \\
Hong Kong & 0.00 & $5.95 \quad * *$ & 1.61 & \\
Japan & 0.01 & 0.43 & 10.14 & $* *$ \\
South Korea & 1.98 & 2.23 & 0.00 & \\
Russia & 0.88 & 0.05 & 4.49 & $* *$ \\
Thailand & 0.87 & 0.02 & 0.00 & \\
UK & 0.00 & 0.14 & 5.04 & $* *$ \\
\hline
\end{tabular}

Note: Tests of contagion from the US equity market to the selected equity markets during the subprime mortgage crisis. ** and * denote significance at the 0.05 and 0.1 level of significance. (a) FR: Forbes and Rigobon Contagion test; (b) $C S_{1}$ : Coskewness contagion test with coskewness measured in terms of the US equity returns and squared returns of the selected markets; (c) $\mathrm{CS}_{2}$ : Coskewness contagion test with coskewness measured in terms of squared US equity returns and returns of the selected markets.

Table 2 presents the results of contagion tests based on changes in correlation (FR) and co-skewness $\left(C S_{1}\right.$ and $\left.C S_{2}\right)$. The table reveals that there is significant evidence of contagion from the returns of the US equity market to the returns of the Australian equity market during the subprime mortgage crisis; while there is no evidence of contagion transmitting from the US equity market to the European equity 
markets. As for the contagion test based on changes in coskewness, the results show that contagion effects are widespread from the US equity market to both Asian and European equity markets during the subprime mortgage crisis. In particular, the key transmission channel is from the returns of equity market in the US to the return volatility in Australia and Hong Kong, and from return volatility of the equity market in the US to the returns of equity in Canada, Germany, Japan, Russia and the UK during the subprime mortgage crisis.

\section{CONCLUSIONS}

This paper studies the contagion tests on equity markets during the subprime mortgage crisis of 2007. We apply two types of contagion tests to test 10 equity markets in Asia and Europe during the subprime mortgage crisis. Two types of contagion tests are the correlation change test (Forbes and Rigobon, 2002) and the coskewness change test (Fry et al., 2010). As for the correlation change test, contagion is defined as a significant increase in correlation during the crisis period compared with the non-crisis period. As for the co-skewness change test, contagion is defined as a significant change in coskewness during the crisis period compared with the noncrisis period. The empirical results show significant evidence of contagion from the US to Asian equity markets based on the correlation change test; while as for the coskewness change test, the results show that significant evidence of contagion from the US equity market to both Asian and European equity markets during the subprime mortgage crisis.

\section{REFERENCES}

[1] K.H. Bae, G.A. Karolyi and R.M. Stulz, "A New Approach to Measuring Financial Contagion,” vol. 16, Review of Financial Studies, 2003, pp.717-63.

[2] R. Dornbusch, Y.C. Park and S. Claessens, "Contagion: Understanding How It Spreads,” vol. 15, The World Bank Research Observer, 2000, pp.177-97.

[3] M. Dungey, R.A. Fry, B. Gonzalez-Hermosillo and V.L. Martin, "Shocks and Systemic Influences: Contagion in Global Equity Markets in 1998," vol. 18, The North American Journal of Economics and Finance, 2007, pp.155-74.

[4] K. Forbes and R. Rigobon, "No Contagion, Only Interdependence: Measuring Stock Market Co-movements,” vol. 57, The Journal of Finance, 2002, pp.2223-61.

[5] R.A. Fry, V.L. Martin and C. Tang, "A New Class of Tests of Contagion with Applications," vol. 28, Journal of Business Economics and Statistics, 2010, pp.423-37.

[6] J. Knight, C. Lizieri and S. Satchell, "Diversification When It Hurts? The Joint Distributions of Real Estate and Equity Markets,” vol. 22, Journal of Property Research, 2005, pp.309-23.

[7] M. Pericoli and M. Sbracia, “A Primer on Financial Contagion,” vol. 17, Journal of Economic Surveys, 2003, pp.571-608. 